\title{
The Protective Effects of the Supercritical-Carbon Dioxide Fluid Extract of Chrysanthemum indicum against Lipopolysaccharide-Induced Acute Lung Injury in Mice via Modulating Toll-Like Receptor 4 Signaling Pathway
}

\author{
Xiao-Li Wu, ${ }^{1,2}$ Xue-Xuan Feng, ${ }^{1}$ Chu-Wen Li, ${ }^{1,3}$ Xiao-Jun Zhang, ${ }^{1}$ Zhi-Wei Chen, \\ Jian-Nan Chen, ${ }^{1,4}$ Xiao-Ping Lai, ${ }^{1,4}$ Sai-Xia Zhang, ${ }^{1}$ Yu-Cui Li, ${ }^{1}$ and Zi-Ren Su ${ }^{1,4}$ \\ ${ }^{1}$ School of Chinese Materia Medica, Guangzhou University of Chinese Medicine, No. 232, Waihuandong Road, \\ Guangzhou Higher Education Mega Center, Guangzhou 510006, China \\ ${ }^{2}$ Faculty of Health Science, University of Macau, Taipa 999078, Macau \\ ${ }^{3}$ State Key Laboratory of Quality Research in Chinese Medicine, Institute of Chinese Medical Sciences, \\ University of Macau, Taipa 999078, Macau \\ ${ }^{4}$ Dongguan Mathematical Engineering Academy of Chinese Medicine, Guangzhou University of Chinese Medicine, \\ Songshan Lake High-Tech Industrial Development Zone, Dongguan, Guangdong 523808, China
}

Correspondence should be addressed to Yu-Cui Li; liyucui@gzucm.edu.cn and Zi-Ren Su; suziren@gzucm.edu.cn

Received 12 January 2014; Revised 15 June 2014; Accepted 22 June 2014; Published 25 August 2014

Academic Editor: Chang Shik Yin

Copyright ( $) 2014$ Xiao-Li Wu et al. This is an open access article distributed under the Creative Commons Attribution License, which permits unrestricted use, distribution, and reproduction in any medium, provided the original work is properly cited.

The supercritical-carbon dioxide fluid extract of Chrysanthemum indicum Linné. (CFE) has been demonstrated to be effective in suppressing inflammation. The aim of this study is to investigate the preventive action and underlying mechanisms of CFE on acute lung injury (ALI) induced by lipopolysaccharide (LPS) in mice. ALI was induced by intratracheal instillation of LPS into lung, and dexamethasone was used as a positive control. Results revealed that pretreatment with CFE abated LPS-induced lung histopathologic changes, reduced the wet/dry ratio and proinflammatory cytokines productions (TNF- $\alpha$, IL-1 $\beta$, and IL-6), inhibited inflammatory cells migrations and protein leakages, suppressed the levels of MPO and MDA, and upregulated the abilities of antioxidative enzymes (SOD, CAT, and GPx). Furthermore, the pretreatment with CFE downregulated the activations of NF- $\kappa \mathrm{B}$ and the expressions of TLR4/MyD88. These results suggested that CFE exerted potential protective effects against LPS-induced ALI in mice and was a potential therapeutic drug for ALI. Its mechanisms were at least partially associated with the modulations of TLR4 signaling pathways.

\section{Introduction}

Acute lung injury (ALI) and its severe form, acute respiratory distress syndrome (ARDS), are clinical problems induced by acute and excessive inflammatory responses to stimulus in the airspaces and lung parenchyma, involving alveolarcapillary membrane damage, neutrophils recruitment, vascular permeability increase, pulmonary edema, and respiratory failure [1-3]. ALI and ARDS are life-threatening problems, always leading to multiple organ dysfunction syndrome (MODS), with significant incidences and mortalities in critically ill patients $[1,2]$. Although the pathologies of ALI have been clearly defined and several candidate therapy strategies have been clinically applied for ALI [3-5], there is still no effective therapy strategy but relatively noteworthy mortality rates $[2,6]$. Therefore, to develop novel effective prevention and therapies is urgently needed.

Lipopolysaccharide (LPS), a major constituent of outer membranes of Gram-negative bacteria, has been defined to be a pivotal risky factor and prominent stimulus in the pathogenesis of ALI $[3,7]$. It has been defined that LPS challenges induce neutrophil infiltrations, trigger acute inflammatory responses, and generate early lung pathological changes, resulting in the morbidity and development 
of ALI $[3,8,9]$. Thus intratracheal instillation of LPS to experimental animals, with clear clinical relations to the process of ALI but no systemic inflammation, is wellsuited and reproducible for preliminarily pharmacological researches of novel drugs or other therapeutic agents [810]. Once entering into the host, LPS activates toll-like receptor 4 (TLR4), a main sensor of the TLR superfamily acting as transmembrane proteins and signal transduction molecules $[5,7,11]$. TLR 4 can activate nuclear factor- (NF-) $\kappa B$ protein through myeloid differentiation factor 88 (MyD88) pathway $[5,11]$. Then the activated NF- $\kappa \mathrm{B}$ induces the productions of proinflammatory cytokines such as tumor necrosis factor- (TNF-) $\alpha$, interleukin- (IL-) $1 \beta$, and IL-6 [1113], resulting in recruitment of intravascular neutrophils into the alveolar space and lung parenchyma [14, 15], followed by protease release and reactive oxygen species (ROS) generation which is closely associated with lipid peroxidation aggravation (such as malondialdehyde, MDA) and antioxidant enzyme (such as superoxide dismutase, SOD; catalase, CAT; and glutathione peroxidase, GPx) activity decline [8, 14]. Hence, drugs focusing on downregulating the TLR4 signaling pathway and/or inhibiting its related inflammatory responses would provide potential therapeutic effects for ALI $[5,11]$.

Chrysanthemum indicum Linné (C. indicum), a traditional Chinese medicine, has long been used in treatments of several acute respiratory system diseases, including cold, cough, acute bronchitis, acute laryngitis, and acute pharyngitis, with high efficacy and low toxicity [16]. The supercriticalcarbon dioxide fluid extract of $C$. indicum (CFE) has been widely applied as a fine material in many TCM preparations, for example, C. indicum granules and capsules [17, 18]. Most importantly, CFE was a key ingredient of a TCM recipe named Compound C. indicum Soft Capsule (also known as $\mathrm{CPZ}$ in previous studies), an anti-influenza drug whose effects were closely associated with anti-inflammatory activity [18]. CFE has also been demonstrated to possess strong anti-inflammatory effects, and the underlying mechanism was related to its upregulations of antioxidant enzymes and downregulations of NF- $\kappa \mathrm{B}$ and some proinflammatory cytokines, such as TNF- $\alpha$, IL-1 $\beta$, and IL-6 $[17,18]$.

Although CFE has shown anti-inflammatory benefits, its potential effects to protect against LPS-induced ALI still remained unclear. Therefore, in this present study, we aimed to evaluate the effect of CFE on LPS-induced ALI in mice. And for potential mechanisms elucidation, the expressions of TLR4/MyD88 and the phosphorylations of NF- $\kappa \mathrm{B}$ p $65 / \mathrm{I} \kappa \mathrm{B} \alpha$ were also evaluated.

\section{Materials and Methods}

2.1. Drugs and Chemicals. Lipopolysaccharide (LPS) and dexamethasone (Dex) were purchased from Sigma Co., Ltd. (St. Louis, USA), and Xianju Pharmaceutical Co., Ltd. (Zhejiang, China), respectively. Phosphate buffered saline (PBS), sodium dodecyl sulphate polyacrylamide gel (SDS-PAGE), skimmed milk, Tween-20, and Tween-80 were purchased from Thermo-Fisher Sci. Co., Ltd. (MA, USA). Hexadecyltrimethylammonium bromide (HTAB) and $o$-dianisidine were purchased from TCI Co., Ltd. (Tokyo, Japan). All other chemicals were of the reagent grade.

2.2. Preparation of CFE. The supercritical fluid $\mathrm{CO}_{2}$ extract of Chrysanthemum indicum Linné (CFE) was prepared and provided by the Institute of New Drug Research \& Development, Guangzhou University of Chinese Medicine (Lot. 20121104). In our previous chemical analysis of CFE, 35 compounds were identified by GC-MS, and 5 compounds were reconfirmed and quantified by HPLC-PAD (the brief chemical profile of CFE is listed in Table 1) [17]. For experiments in this paper, CFE samples were diluted by $0.5 \%$ Tween- 80 into the appropriate dose.

2.3. Experimental Animals. Male Kunming (KM) mice (20$25 \mathrm{~g}$ ) were purchased from Medical Laboratory Animal Center of Guangdong Province (Certificate number SCXK20080002, Guangdong Province, China). Animals were kept on 12-hour light/12-hour dark cycles under regular temperature $\left(22 \pm 2^{\circ} \mathrm{C}\right)$ and humidity $(50 \pm 10 \%)$ with standard diets and clean water ad libitum. All animals were sacrificed by lethal sodium pentobarbital injection. All experiments were conducted according to the National Institutes of Health Guide for the Care and Use of Laboratory Animals and approved by the Institutional Animal Care and Use Committee of Guangzhou University of Chinese Medicine.

\subsection{Experimental Designs}

2.4.1. Positive Control Setting, Animal Groups, and LPSInduced ALI. Dex has been frequently used as a positive control agent in various kinds of ALI models in experimental settings. With the definite and proved benefits and effects, Dex is applicable to be the positive control agent for screening and evaluating new therapeutic agents [19-21]. Therefore, Dex was selected as the positive control agent and a common dose of $5 \mathrm{mg} / \mathrm{kg}$ (p.o.) used in this study [19-21].

To assess mortality rate, 120 mice were randomly divided into 5 groups $(n=24)$, sham group, LPS group, and CFE $(40,80$ and $120 \mathrm{mg} / \mathrm{kg}$ ) groups. CFE groups were given CFE (40, 80, and $120 \mathrm{mg} / \mathrm{kg}$, p.o.) while sham group and LPS group were given Tween-80, for 7 consecutive days. One hour after the last administration, all animals were anesthetized. And mice from LPS group and CFE groups were given a single intratracheal instillation of $20 \mathrm{mg} / \mathrm{kg}$ LPS $(10 \mathrm{mg} / \mathrm{mL}$, dilution with PBS; $20 \mu \mathrm{L} / 10 \mathrm{~g}$ body weight) while mice from the sham group were given an equal volume of PBS. After operation, mice of all groups were monitored and the time when any animal died was recorded every 6 hours up to 120 hours. Then the mortality rate of each group within 120 hours was calculated and compared using the Kaplan Meier methods.

In the other experiments, mice were randomly divided into 6 groups $(n=30)$, sham group, LPS group, CFE $(40,80$, and $120 \mathrm{mg} / \mathrm{kg})$ groups, and Dex group $(5 \mathrm{mg} / \mathrm{kg})$. CFE groups and Dex group were given CFE $(40,80$, and $120 \mathrm{mg} / \mathrm{kg}$, p.o.) and Dex (5 mg/kg, p.o.) once per day for 7 consecutive days, respectively. During this period, sham group and LPS group were given equal volumes of 
TABLE 1: The chemical profile of CFE.

\begin{tabular}{|c|c|c|}
\hline Number & Components & Percentage (\%) \\
\hline 1 & Camphene & $0.475^{\mathrm{a}}$ \\
\hline 2 & $\beta$-Cymene & $0.998^{\mathrm{a}}$ \\
\hline 3 & Eucalyptol & $3.091^{\mathrm{a}}$ \\
\hline 4 & Linalool oxide & $0.521^{\mathrm{a}}$ \\
\hline 5 & $\alpha$-Thujone & $2.186^{\mathrm{a}}$ \\
\hline 6 & $\beta$-Thujone & $2.169^{\mathrm{a}}$ \\
\hline 7 & Isothujol & $1.094^{\mathrm{a}}$ \\
\hline 8 & L-Pinocarveol & $0.765^{\mathrm{a}}$ \\
\hline 9 & d-Camphor & $8.582^{\mathrm{a}}$ \\
\hline 10 & cis-Verbenol & $4.720^{\mathrm{a}}$ \\
\hline 11 & endo-Borneol & $7.845^{\mathrm{a}}$ \\
\hline 12 & L-4-Terpineol & $1.634^{\mathrm{a}}$ \\
\hline 13 & $\alpha$-Terpineol & $1.022^{\mathrm{a}}$ \\
\hline 14 & Myrtenol & $1.054^{\mathrm{a}}$ \\
\hline 15 & Cumaldehyde & $0.486^{\mathrm{a}}$ \\
\hline 16 & Bornyl acetate & $2.948^{\mathrm{a}}$ \\
\hline 17 & Thymol & $3.071^{\mathrm{a}}$ \\
\hline 18 & $\beta$-Caryophyllene & $3.336^{\mathrm{a}}$ \\
\hline 19 & cis- $\beta$-Farnesene & $2.270^{\mathrm{a}}$ \\
\hline 20 & $\alpha$-Curcumene & $5.932^{\mathrm{a}}$ \\
\hline 21 & $\delta$-Cadinene & $1.815^{\mathrm{a}}$ \\
\hline 22 & Spathulenol & $1.362^{\mathrm{a}}$ \\
\hline 23 & Caryophyllene oxide & $8.460^{\mathrm{a}}$ \\
\hline 24 & $\gamma$-Eudesmol & $1.568^{\mathrm{a}}$ \\
\hline 25 & T-Muurolol & $1.487^{\mathrm{a}}$ \\
\hline 26 & $\alpha$-Gurjunene & $2.161^{\mathrm{a}}$ \\
\hline 27 & Aromadendrene & $2.280^{\mathrm{a}}$ \\
\hline 28 & $\alpha$-Bisabolol & $2.289^{\mathrm{a}}$ \\
\hline 29 & Cubenol & $1.742^{\mathrm{a}}$ \\
\hline 30 & Longifolenaldehyde & $2.572^{\mathrm{a}}$ \\
\hline 31 & $\alpha$-Bisabolol oxide & $2.600^{\mathrm{a}}$ \\
\hline 32 & Hexahydrofarnesyl acetone & $1.212^{\mathrm{a}}$ \\
\hline 33 & Ethyl hexadecanoate & $1.362^{\mathrm{a}}$ \\
\hline 34 & $\alpha$-Linolenic acid & $2.130^{\mathrm{a}}$ \\
\hline 35 & Ethyl octadec-9,12-dienoate & $2.470^{\mathrm{a}}$ \\
\hline 36 & Chlorogenic acid & $2.110^{\mathrm{b}}$ \\
\hline 37 & Luteolin-7-glucoside & $2.800^{\mathrm{b}}$ \\
\hline 38 & Linarin & $4.830^{\mathrm{b}}$ \\
\hline 39 & Luteolin & $1.140^{\mathrm{b}}$ \\
\hline 40 & Acacetin & $0.880^{\mathrm{b}}$ \\
\hline
\end{tabular}

${ }^{a}$ Identified by GC-MS analysis and the relative percentage calculated by integrated peak area in Agilent MSD Chemstation data analysis program.

${ }^{\mathrm{b}}$ Identified and quantified by HPLC-PAD analysis, and the relative percentage was represented by the content quantitatively analyzed with peak areas under the standard curves.

Tween-80. One hour after the last administration, mice were anesthetized via intraperitoneally injecting pentobarbital sodium $(30 \mathrm{mg} / \mathrm{kg})$. After that, mice from LPS group, Dex group, and CFE groups were given a single intratracheal instillation of $5 \mathrm{mg} / \mathrm{kg}$ LPS $(2.5 \mathrm{mg} / \mathrm{mL}$, freshly diluted with PBS; $20 \mu \mathrm{L} / 10 \mathrm{~g}$ body weight) while mice of sham group were given an equal volume of PBS. In this model, all animals survived for 24 hours after the intratracheal instillation of LPS at the dose of $5 \mathrm{mg} / \mathrm{kg}$, which was optimized and repeatable, based on our preliminary experiments (data were not provided).

2.4.2. Specimen Collections. 24 hours after LPS instillation, 30 mice of each group were randomly divided into 3 parts, 10 mice per part. Part 1 was used for the bronchoalveolar lavage fluid (BALF) preparation and the lung wet/dry weight (W/D) ratio measurement. In brief, after anaesthetization, mouse was surgically exposed the trachea and clamped the right main bronchus. Then the left lung of each animal was lavaged for three times with a total volume of $1.5 \mathrm{~mL}$ of Hanks-Balanced-Salt solution using a venous indwelling needle. The BALF recovery rate was more than $90 \%$. Then the mouse was sacrificed, and right lung was harvested for the W/D ratio measurement. Part 2 was used for the lung tissue preparation and the histopathologic evaluation. In brief, after the mouse was sacrificed, the left lung was taken, placed in appropriate amount of precold PBS immediately, and homogenized using a Tissue Lyser II high-throughput tissue homogenization system (Qiagen Co., Ltd., Hilden, Germany). Then the homogenate was centrifuged at $4^{\circ} \mathrm{C} .100 \mu \mathrm{L}$ of the supernatant was used for protein measurement and the rest was immediately collected and stored at $-80^{\circ} \mathrm{C}$ for further analysis of MPO, MDA, proinflammatory cytokines (TNF- $\alpha$, IL-1 $\beta$, and IL-6), and antioxidant enzymes (SOD, CAT, and GPx). At the same time, the right lung was harvested for the histopathologic examination. Part 3 was left for western-blot assay of TLR4, MyD88, NF- $\kappa \mathrm{B}$ p65, and I $\kappa \mathrm{B} \alpha$. In brief, mouse was sacrificed, and the lung tissues were harvested, frozen, and stored in liquid nitrogen immediately.

2.5. Measurement of Lung W/D Ratio. The lung W/D ratio was measured according to the previous study. In brief, the excised right lung was blotted dry and weighed to obtain the "wet" weight, afterwards kept in an oven at $80^{\circ} \mathrm{C}$ for 48 hours to obtain the "dry" weight. Then the W/D ratio was calculated by the "wet" weight to the "dry" weight.

\subsection{Measurement of BALF Protein Contents and BALF Cell} Counts. The BALF was centrifuged at $800 \times \mathrm{g}$ for $10 \mathrm{~min}$ at $4^{\circ} \mathrm{C}$, and the supernatant was collected for measurement of protein content. Measurements of protein contents of BALF were performed using a commercial BCA kit (Beyotime Institute of Biotechnology, Shanghai, China) and expressed as $\mathrm{mg} / \mathrm{mL}$ BALF. Then sediment cells were resuspended in precold PBS and stained by a Wright-Giemsa kit (Nanjing Jiancheng Bioengineering Institute, Nanjing, China) for cytospin preparations. Counts of the total cells, neutrophils, and macrophages were then double-blindly performed via hemacytometry.

2.7. MPO Assay. The assay of MPO activity was performed via the $\mathrm{HTAB}$ method. Briefly, the samples were mixed with $\mathrm{KPO}_{4}$ buffer $(50 \mathrm{mM}$, pH 6.0) with $\mathrm{HTAB}(0.5 \%)$. After reacting and incubating at $37^{\circ} \mathrm{C}$ for $15 \mathrm{~min}$, the enzyme was assayed by the activity in a $\mathrm{H}_{2} \mathrm{O}_{2} / o$-dianisidine buffer at 
$460 \mathrm{~nm}$ with a Multiskan GO microplate spectrophotometer (Thermo-Fisher Sci., Waltham, USA). Results were expressed as units/mg protein.

2.8. Histopathologic Examination. Biopsies of right lungs were collected, fixed in $4 \%$ paraformaldehyde solution, dehydrated, embedded with paraffin, and sectioned into $4 \mu \mathrm{m}$. Tissue sections were stained with hematoxylin and eosin kit (H\&E, Beyotime Institute of Biotechnology), examined, and photographed using TE2000-S Inverted Microscopes (Nikon Co., Ltd., Tokyo, Japan). According to previous reports, histologic changes including neutrophil infiltration, interstitial edema, congestion (or hemorrhage), and hyaline membrane formation were evaluated and the severity of each change was scored on a scale of 0 (normal) to 4 (severe) by a pathologist blinded to this study. Finally, the overall histologic injury was evaluated according to the sum-scores ( 0 as normal, 1 to 5 as minimal; 6 to 10 as mild; 11 to 15 as moderate; 16 to 20 as severe). Results were presented as the means of scores of microscopic areas of each group.

2.9. MDA, SOD, CAT, and GPx Assay. The MDA assay was carried out with commercial MDA assay kits (Beyotime Institute of Biotechnology) via the method of thiobarbituric acid reacting substance (TBARS). In Brie, reaction between MDA and TBARS was performed at $100^{\circ} \mathrm{C}$, resulting in formation of a red complex TBARS, which could be recorded and measured at $532 \mathrm{~nm}$. SOD, CAT, and GPx were measured using commercially available kits (Beyotime Institute of Biotechnology) according to the manufacturers' instructions, respectively. Briefly, xanthine and xanthine oxidase (XOD) generated superoxide radicals and reacted with 2-(4-iodophenyl)-3-(4-nitrophenol)5-phenyltetrazolium chloride to form a red formazan dye, which could be measured at $532 \mathrm{~nm}$. CAT was measured by the production of $\mathrm{N}$-(4-antipyryl)-3-chloro-5-sulfonatep-benzoquinonemonoimine, which would be detected at $520 \mathrm{~nm}$. And GPx was measured by detecting contents of GRd and NADPH, which would be recorded at $340 \mathrm{~nm}$.

2.10. ELISA Assay for TNF- $\alpha, I L-1 \beta$, and IL-6. TNF- $\alpha$, IL$1 \beta$, and IL- 6 were measured using commercially available ELISA kits ( $e$ Bioscience Co., Ltd., CA, USA). In brief, diluted standards or samples were added to 96-well plates precoated with affinity purified polyclonal antibodies specific for mouse TNF- $\alpha$, IL- $1 \beta$, and IL-6, respectively. Then wells were added with enzyme linked polyclonal antibodies and incubated at $37^{\circ} \mathrm{C}$ for $60 \mathrm{~min}$, followed by final washes for 5 times. The intensities detected at $450 \mathrm{~nm}$ were measured after addition of substrate solutions for $15 \mathrm{~min}$. Levels of TNF- $\alpha$, IL- $1 \beta$, and IL- 6 were calculated according to standard curves.

2.11. Western-Blot Assay for TLR4, MyD88, and NF- $\kappa B$. Extractions of proteins from the lung tissues were performed with T-PER tissues proteins extractions reagent kits (Beyotime Institute of Biotechnology). Extractions of nuclear and cytoplasmic proteins from the lungs were performed with nuclear and cytoplasmic proteins extractions reagent

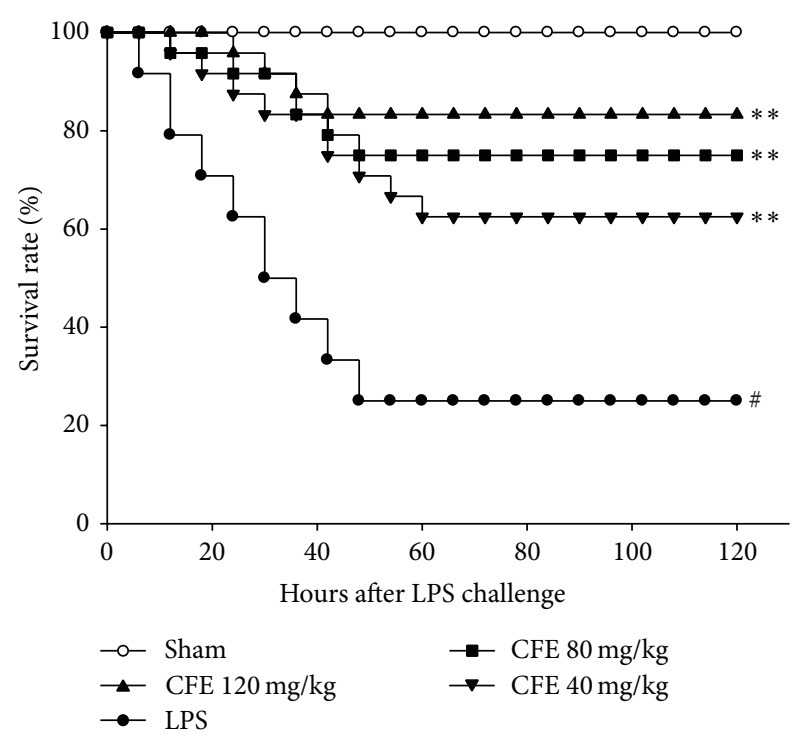

FIGURE 1: The effect of CFE on survival rates. Data was represented as the mean $\pm \operatorname{SEM}(n=24) .{ }^{\#} P<0.01$ compared to the sham group; ${ }^{*} P<0.05$ and ${ }^{* *} P<0.01$ compared to the LPS group.

kits (Beyotime Institute of Biotechnology). Protein contents were measured using BCA protein assay kits and equal amounts of protein were added in per well on $10 \%$ SDS PAGE. Then, proteins were separated and transferred into PVDF membranes by an Electrophoresis System (Bio-rad Co., Ltd., Hercules, USA). The resulting membranes were blocked with Tris-buffered-saline containing 0.05\% Tween20 (TBS-T), supplemented with 5\% skimmed milk at room temperature for 2 hours, and followed by TBS-T washings. Then membranes were incubated with related specific primary antibodies anti-NF- $\kappa \mathrm{B}$ p 65 antibody, anti-I $\kappa \mathrm{B} \alpha$ antibody (Cell Signaling Technology Co., Ltd., MA, USA), antiTLR4 antibody, and anti-MyD88 antibody (Santa Cruz Co., Ltd., TX, USA) at $4^{\circ} \mathrm{C}$ overnight, respectively, followed by washes with TBS-T and incubation with the peroxidaseconjugated secondary antibody at room temperature for 1 hour. The detections of labeling proteins were performed with enhanced-chemiluminescence western-blotting detections kits. And the relative protein levels were normalized to $\beta$-actin (Santa Cruz Co., Ltd.) protein as the internal standard.

2.12. Statistical Analysis. Data were presented as the mean \pm SEM and statistical analyses were performed with Systat Sigma Plot software (version 12.00 for windows). Parametric data were analyzed by one-way ANOVA, followed by TukeyKramer test, and nonparametric data were analyzed by Kruskal-Wallis test, followed by Dunn's test. The mortality studies were analyzed by the Kaplan-Meier method. And $P<$ 0.05 was considered to be statistically significant.

\section{Results}

3.1. The Effects of CFE on Survival Rates. As shown in Figure 1, compared to the sham group with the survival rate of $100.0 \%$, 


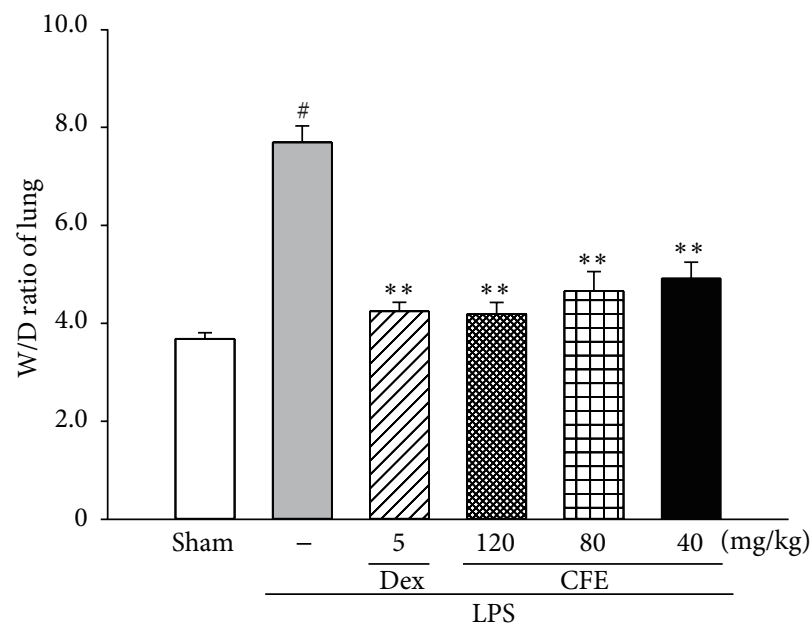

(a)

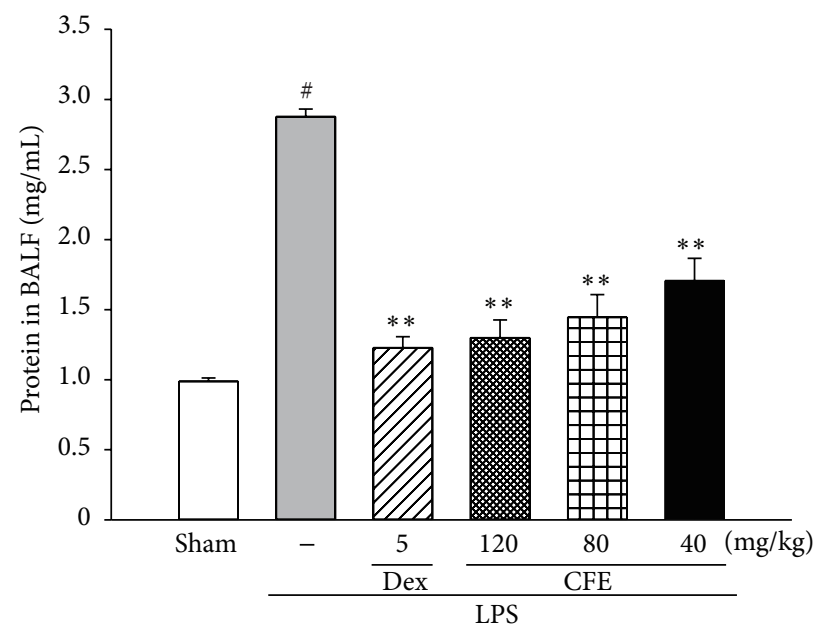

(b)

FIgURE 2: The effects of CFE on lung W/D ratio (a) and BALF protein content (b). Data was represented as the mean \pm SEM $(n=10)$. ${ }^{\#} P<0.01$ compared to the sham group; ${ }^{*} P<0.05$ and ${ }^{* *} P<0.01$ compared to the LPS group.

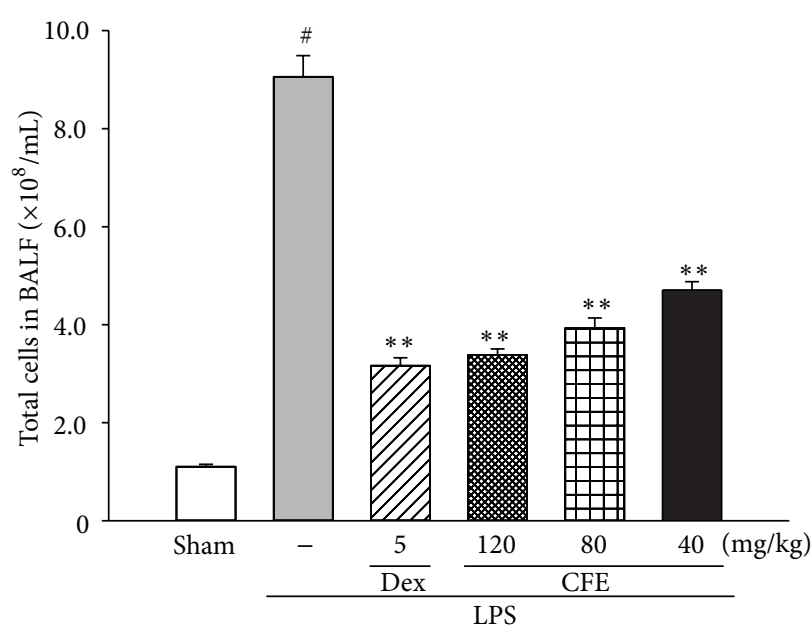

(a)

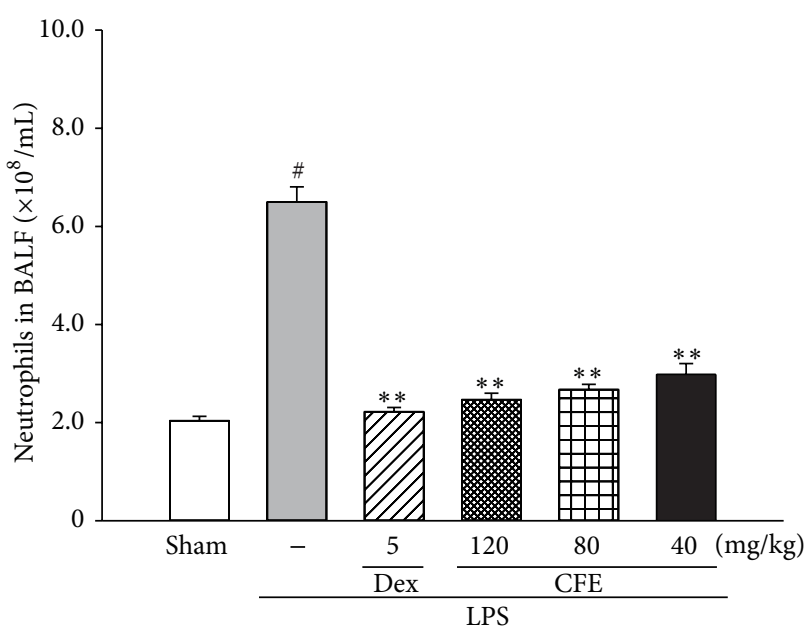

(b)

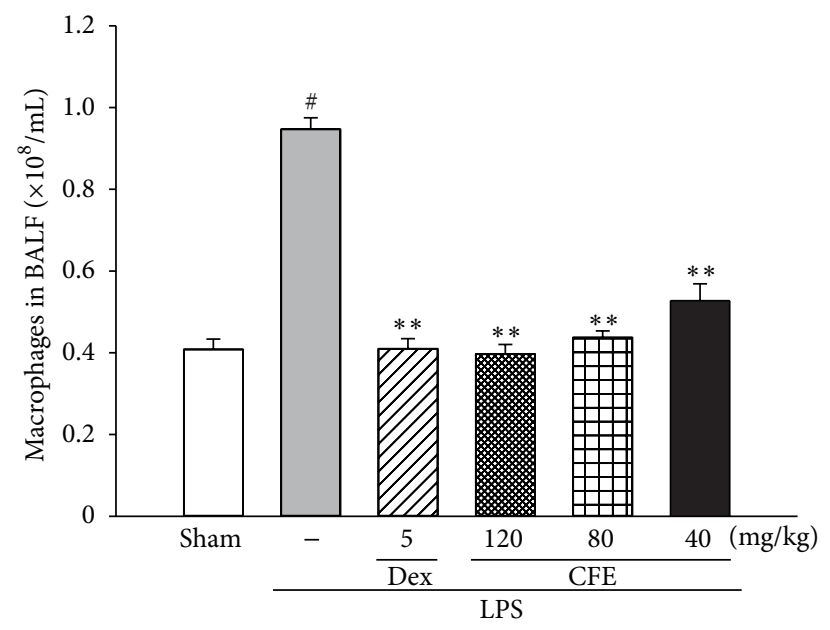

(c)

FIGURE 3: The effects of CFE on total cells (a), neutrophils (b), and macrophages (c) in BALF. Data was represented as the mean \pm SEM $(n=10) .{ }^{\#} P<0.01$ compared to the sham group; ${ }^{*} P<0.05$ and ${ }^{* *} P<0.01$ compared to the LPS group. 


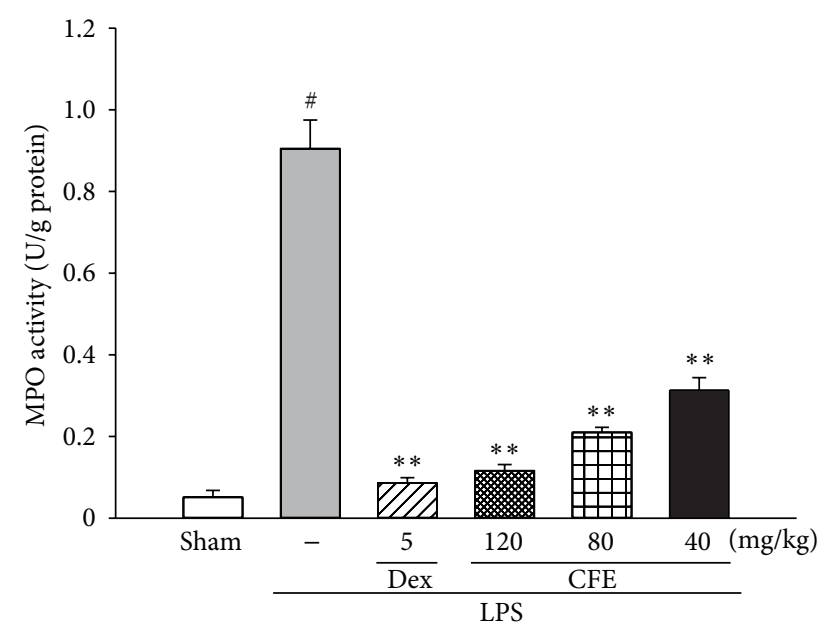

FIGURE 4: The effects of CFE on MPO activity. Data was represented as the mean $\pm \operatorname{SEM}(n=10) .{ }^{\#} P<0.01$ compared to the sham group; ${ }^{*} P<0.05$ and ${ }^{* *} P<0.01$ compared to the LPS group.

LPS challenge markedly declined the survival rate of the LPS group to about $25.0 \%$ within 120 hours $11(P<0.01)$. Conversely, survival rates of CFE-treated groups $(40,80$, and $120 \mathrm{mg} / \mathrm{kg}$ ) significantly increased to $62.5 \%, 75.0 \%$, and $83.3 \%$, respectively, in a dose-dependent manner (for all, $P<0.01$ versus the LPS group). Data indicated that CFE pretreatment possessed potential prevention against mortality in ALI mice induced by LPS.

3.2. The Effects of CFE on Lung W/D Ratio. The W/D ratio of ALI mice was evaluated to assess the severity of pulmonary edema. And as shown in Figure 2(a), when compared with the sham group, there was a significant increase (approximately 2 -fold) in the lung W/D ratio of the LPS group $(P<$ $0.01)$. However, with the pretreatments of CFE $(40,80$, and $120 \mathrm{mg} / \mathrm{kg}$ ), the levels of lung W/D ratio were dosedependently suppressed, as compared to the LPS group (for all, $P<0.01$ ). Data showed that the lung W/D ratio was significantly suppressed by pretreatment with CFE.

3.3. The Effects of CFE on BALF Protein Content. The vascular permeability of the lung in mice was measured by the protein content of BALF. As compared to the sham group, LPS significantly boosted the BALF protein level of the LPS group $(P<0.01$, Figure $2(\mathrm{~b}))$. On the contrary, the protein contents of CFE groups $(40,80$, and $120 \mathrm{mg} / \mathrm{kg}$ ) were markedly suppressed in a dose-dependent manner, when compared with the LPS group (for all, $P<0.01$ ).

3.4. The Effects of CFE on Cell Counts of BALF. As shown in Figure 3, the BALF cell counts of LPS group demonstrated significant increases in the total cells (Figure 3(a)), neutrophils (Figure 3(b)), and macrophages (Figure 3(c)) $(P<0.01$ versus the sham). However, pretreatments with CFE $(40,80$, and $120 \mathrm{mg} / \mathrm{kg})$ and Dex $(5 \mathrm{mg} / \mathrm{kg})$ markedly decreased all relevant cell counts in CFE groups and Dex group, respectively, (for all, $P<0.01$ versus the LPS group).
3.5. The Effects of CFE on MPO Activity. MPO served as a functional index indicating neutrophils infiltration, which represented the levels of MPO-derived oxidants generation and lung tissue damage $[5,8,14]$. As expected outcomes of the LPS group, the MPO activity in lung tissue, was significantly elevated, about 9 folds of the sham group $(P<0.01$, versus the sham group), which was shown in Figure 4 . However, when compared to the LPS group, the MPO activities of the CFEtreated $(40,80$, and $120 \mathrm{mg} / \mathrm{kg})$ and Dex-treated $(5 \mathrm{mg} / \mathrm{kg})$ groups were significantly inhibited (for all, $P<0.01$ ).

3.6. The Effects of CFE on Histopathological Examination. Histopathological analyses were performed to investigate the effects of CFE on physiological parameters. As expected, the sham group displayed normal structures and no histopathological change in lung tissues (Figure 5(a)). On the other hand, with the challenge of LPS, the pulmonary function of LPS group was obviously impaired, with various histopathologic changes including haemorrhage, interstitial edema, thickening of the alveolar wall, and infiltration of inflammatory cells into the lung parenchyma and alveolar spaces (Figure 5(b)). As for experimental groups and positive group, histopathological changes were obviously abated by pretreatments of Dex (Figure 5(c)) and CFE $(40 \mathrm{mg} / \mathrm{kg}$, Figure 5(d); $80 \mathrm{mg} / \mathrm{kg}$, Figure 5(e); and $120 \mathrm{mg} / \mathrm{kg}$, Figure 5(f)), respectively, when compared to the LPS group. In addition, similarly inhibitory effects were found in semiquantitative assay by the histologic changes' scorings, which promoted the evaluation of severity of ALI (Figure 5(g)). Results demonstrated that pretreatment with CFE attenuated the severity of lungs injuries of ALI mice induced by LPS and improved the condition of lungs' tissues, in a dose-dependent manner.

3.7. The Effects of CFE on MDA, SOD, CAT, and GPX Levels. Oxidative stress plays vital important roles in the process of ALI induced by LPS, and oxidative damage induces lipid peroxidation of membrane phospholipids and inactivation of antioxidative enzymes (SOD, CAT, and GPx), while culminating in the MDA generation $[5,8,14]$. In the LPS group, MDA level in lung tissue was remarkably increased, compared to the sham group $(P<0.01)$, shown in Table 2 . However, groups pretreated with CFE $(40,80$, and $120 \mathrm{mg} / \mathrm{kg}$ ) as well as Dex $(5 \mathrm{mg} / \mathrm{kg})$ showed significant declines in the MDA level (for all, $P<0.01$ versus the LPS group). In addition, the activities of SOD, CAT, and GPx in LPS group were significantly abated, when compared with the sham group (for all, $P<0.01$ ), as presented in Table 2. On the contrary, pretreatments with CFE $(40,80$, and $120 \mathrm{mg} / \mathrm{kg})$ significantly boosted the SOD, CAT, and GPx activities (for all, $P<0.01$ versus the LPS group), in a dose-dependent manner.

3.8. The Effects of CFE on TNF- $\alpha$, IL-1 1 , and IL-6 Levels. As compared to the sham group, the levels of TNF- $\alpha$, IL- $1 \beta$, and IL-6 in LPS group were remarkably raised (for all, $P<0.01$, Table 3). Administration with CFE $(40,80$, and $120 \mathrm{mg} / \mathrm{kg})$ had inhibitory effects on the level of TNF- $\alpha(P<0.05$, versus 


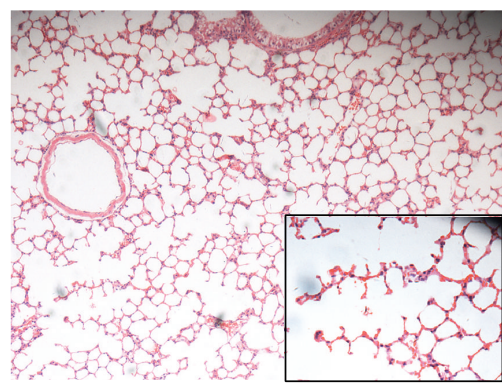

(a)

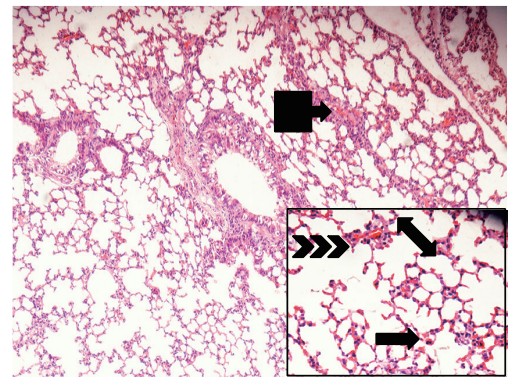

(d)

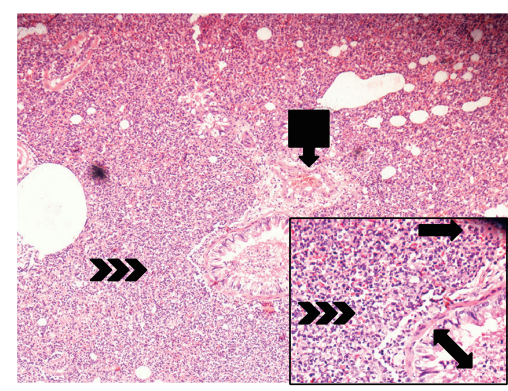

(b)

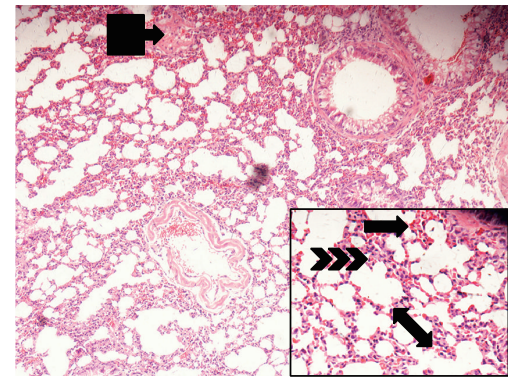

(e)

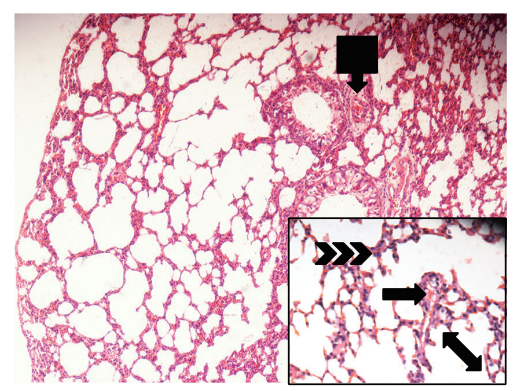

(c)

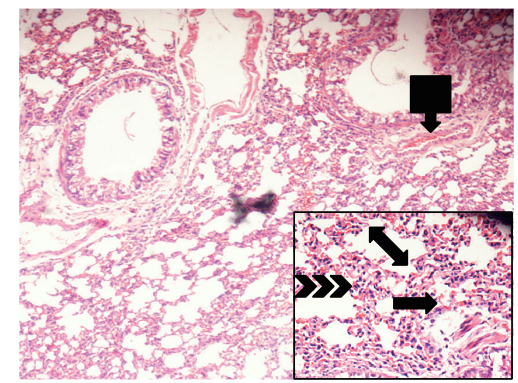

(f)

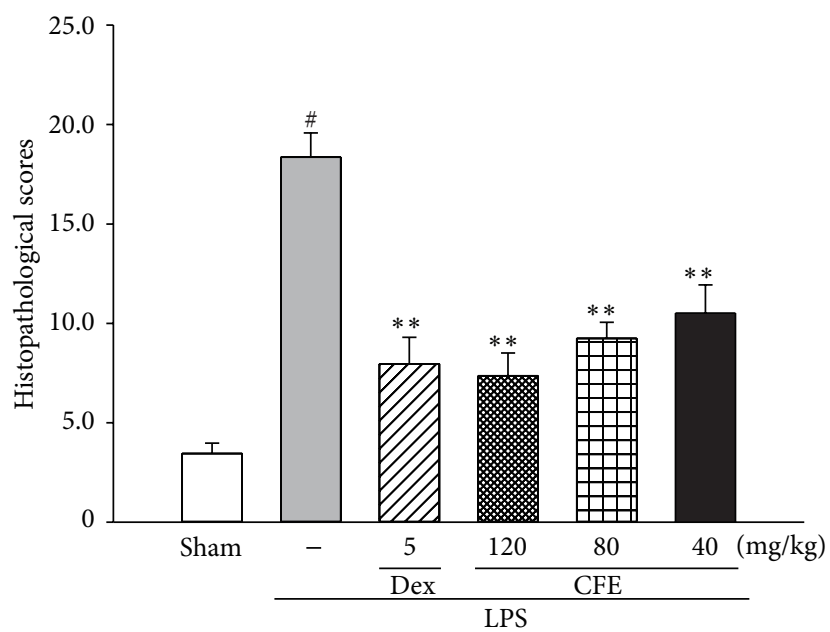

(g)

Figure 5: The effects of CFE on histopathological examination. Sham (a), LPS (b), LPS + 5 mg/kg Dex (c), LPS + 120 mg/kg CFE (d), LPS + $800 \mathrm{mg} / \mathrm{kg}$ CFE (e), LPS $+40 \mathrm{mg} / \mathrm{kg}$ CFE (f), and histologic changes scorings (G) (100x and 400x). Data was represented as the mean \pm SEM $(n=10) .{ }^{\#} P<0.01$ compared to the sham group; ${ }^{*} P<0.05$ and ${ }^{* *} P<0.01$ compared to the LPS group. Haemorrhage: $\longrightarrow ;$ interstitial edema: $\longrightarrow$; thickening of the alveolar wall: $\longleftrightarrow$; and infiltration of inflammatory cells:

$2 \mathbf{3}$.

TABLE 2: The effects of CFE on LPS-induced the levels of MDA, SOD, CAT, and GPx.

\begin{tabular}{lcccc}
\hline Groups & MDA (nmol/mg protein) & SOD (U/mg protein) & CAT (U/mg protein) & GPx (U/mg protein) \\
\hline Sham & $0.29 \pm 0.02$ & $1.03 \pm 0.08$ & $0.67 \pm 0.05$ & $0.32 \pm 0.04$ \\
LPS & $1.18 \pm 0.10^{*}$ & $0.31 \pm 0.02^{*}$ & $0.11 \pm 0.03^{*}$ & $0.10 \pm 0.03^{*}$ \\
Dex $(5 \mathrm{mg} / \mathrm{kg})$ & $0.62 \pm 0.06^{* *}$ & $0.57 \pm 0.06^{* *}$ & $0.39 \pm 0.06^{* *}$ & $0.17 \pm 0.03^{* *}$ \\
CFE $(120 \mathrm{mg} / \mathrm{kg})$ & $0.49 \pm 0.06^{* *}$ & $0.62 \pm 0.05^{* *}$ & $0.42 \pm 0.03^{* *}$ & $0.20 \pm 0.02^{* *}$ \\
CFE $(80 \mathrm{mg} / \mathrm{kg})$ & $0.53 \pm 0.04^{* *}$ & $0.53 \pm 0.05^{* *}$ & $0.38 \pm 0.05^{* *}$ & $0.17 \pm 0.05^{* *}$ \\
CFE $(40 \mathrm{mg} / \mathrm{kg})$ & $0.56 \pm 0.06^{* *}$ & $0.44 \pm 0.05^{* *}$ & $0.36 \pm 0.06^{* *}$ & $0.16 \pm 0.02^{* *}$ \\
\hline
\end{tabular}

Data represented the mean \pm SEM $(n=10) .{ }^{\#} P<0.01$ compared to the sham group; ${ }^{*} P<0.05$ and ${ }^{* *} P<0.01$ compared to LPS group. 
TABLE 3: The effects of CFE on LPS-induced the levels of TNF- $\alpha$, IL-1 $\beta$, and IL-6.

\begin{tabular}{lccc}
\hline Groups & TNF- $\alpha$ (pg/mg protein) & IL-1 $\beta$ (ng/mg protein) & IL-6 (ng/mg protein) \\
\hline Sham & $31.97 \pm 2.47$ & $2.36 \pm 0.22$ & $5.52 \pm 0.74$ \\
LPS & $123.7 \pm 49.36^{\#}$ & $13.41 \pm 1.13^{*}$ & $20.20 \pm 2.47^{*}$ \\
Dex $(5 \mathrm{mg} / \mathrm{kg})$ & $79.81 \pm 13.56^{* *}$ & $5.28 \pm 0.61^{* *}$ & $9.66 \pm 1.57^{* *}$ \\
CFE $(120 \mathrm{mg} / \mathrm{kg})$ & $69.49 \pm 9.71^{* *}$ & $5.67 \pm 0.83^{* *}$ & $10.80 \pm 1.69^{* *}$ \\
CFE $(80 \mathrm{mg} / \mathrm{kg})$ & $77.43 \pm 11.29^{* *}$ & $6.08 \pm 0.52^{* *}$ & $11.96 \pm 1.21^{* *}$ \\
CFE $(40 \mathrm{mg} / \mathrm{kg})$ & $93.49 \pm 6.50^{*}$ & $7.92 \pm 1.24^{*}$ & $12.33 \pm 1.09^{* *}$ \\
\hline
\end{tabular}

Data represented the mean $\pm \operatorname{SEM}(n=10) .{ }^{\#} P<0.01$ compared to the sham group; ${ }^{*} P<0.05$ and ${ }^{* *} P<0.01$ compared to LPS group.

the LPS group). In addition, pretreatment with CFE $(40,80$, and $120 \mathrm{mg} / \mathrm{kg}$ ) downregulated the levels of IL-1 $\beta$ and IL-6, as compared to the LPS group (for all, $P<0.05$ ).

\subsection{The Effects of CFE on TLR4/MyD88/NF- $\kappa B$ Expressions.} In order to probe the potential mechanisms of CFE in protection of LPS-induced ALI in mice, the expressions of TLR4, MyD88, and NF- $\kappa$ B in lungs were further investigated. As shown in Figure 6, data of western-blot displayed that the expressions of TLR4/MyD88/NF- $\kappa$ B signaling pathways were activated by LPS in the LPS group (for all, $P<0.01$, versus the sham group). However, pretreatments with $\mathrm{CFE}$ ( 80 and $120 \mathrm{mg} / \mathrm{kg}$ ) inhibited the phosphorylation of $\mathrm{I} \kappa \mathrm{B} \alpha$ and the expressions of TLR4 and MyD88 (for all, $P<0.05$, versus the LPS group), despite the fact that the low dose of $40 \mathrm{mg} / \mathrm{kg}$ did not reduce the phosphorylation levels of $\mathrm{I} \kappa \mathrm{B} \alpha$ and MyD88, statistically. On the other hand, in CFE (80 and $120 \mathrm{mg} / \mathrm{kg}$ ) groups, the expressions of p65 subunit NF$\kappa \mathrm{B}$ in lungs were downregulated in nucleus and upregulated in cytoplasm, and the levels of $\mathrm{I} \kappa \mathrm{B} \alpha$ increased significantly (for all, $P<0.01$, versus the LPS group), as shown in Figure 6. In this study, results showed that pretreatment with CFE (80 and $120 \mathrm{mg} / \mathrm{kg}$ ) possessed simultaneous and efficient downregulations of TLR4 and MyD88-dependent $\mathrm{NF}-\kappa \mathrm{B}$ signaling pathways, in LPS-induced ALI mice.

\section{Discussions}

In this present study, we evaluated the effects of CFE on LPS-induced ALI in mice. And data demonstrated that CFE abated LPS-induced lung histopathologic changes, declined the wet/dry ratio and proinflammatory cytokines productions, inhibited inflammatory cells migrations and protein leakages into the lungs, suppressed the levels of MPO and lipid peroxidation, upregulated the abilities of antioxidative enzyme, and downregulated the activations of NF- $\kappa \mathrm{B}$ and the expressions of TLR4 and MyD88. These suggested that CFE exerted potential protective effects against LPS-induced ALI.

LPS challenge leads to the leakages of serous fluids into lung tissues, resulting in the pulmonary oedema, a typical symptom of acute inflammatory responses in lung [22]. And pulmonary oedema is always evaluated via measuring a representative index, the lung W/D ratio [22, 23]. Based on the dose-dependent attenuation of the lung W/D ratio in CFE (40, 80, and $120 \mathrm{mg} / \mathrm{kg}$ ) pretreated groups, pretreatment with CFE showed a significant inhibition of the pulmonary edema in ALI mice. On the other hand, the BALF total protein content, an index of lung permeability, was downregulated by pretreatment of CFE; it also demonstrated that pretreatment with CFE (40, 80, and $120 \mathrm{mg} / \mathrm{kg}$ ) possessed attenuation action on lung permeability enhanced by LPS. LPS challenge also directly stimulates the infiltrations of inflammatory cells. Particularly, neutrophils migrating into the lung parenchyma and alveolar space have been indicated to have critical roles in the process of ALI [23, 24]. Neutrophils secrete MPO and lead to productions of MPO-derived oxidants and damage of lung tissues $[23,24]$. Therefore the infiltration of neutrophils is usually represented by the ability of MPO $[23,24]$. As expected, data showed that mice with LPS challenge presented massive infiltrations of inflammatory cells, including neutrophils and macrophages into the lung. However, pretreatment with CFE improved these changes by significantly decreasing the numbers of cells and abating LPSinduced increasing of MPO activity. These results also further proved that neutrophil respiratory burst and lung tissue damage were attenuated by CFE treatment. In addition, results of histopathologic examinations in lung tissues revealed that inflammatory responses and lung injuries in ALI mice were attenuated by CFE treatment in a dose-dependent manner. In summary, results of the alveolar-capillary barrier and inflammatory response as well as histological evidences demonstrated that CFE possessed significantly protective effects on LPS-induced ALI in mice.

Oxidative stress in lung tissue is also an important factor in the pathogenesis of ALI $[5,25,26]$; therefore, oxidative stress in the lung tissue was evaluated. Nowadays, the level of reactive oxygen species (ROS) is known as a classical index of oxidative stress $[5,26,27]$. ROS are chemically reactive molecules containing oxygen and are easy to react with biological macromolecules leading to lipid peroxidation, proteins inactivation, DNAs mutation, and finally tissue damage $[5,26,27]$. In the early stage of ALI induced by LPS, responses of neutrophils, including respiratory burst and degranulation, stimulate cells to rapidly release ROS, such as superoxide radicals $\left(\mathrm{O}_{2} \bullet^{-}\right)$, hydrogen peroxide $\left(\mathrm{H}_{2} \mathrm{O}_{2}\right)$, and hydroxyl radicals $\left(\mathrm{OH} \bullet^{-}\right)[25,27,28]$. On the other hand, $\mathrm{MPO}$ is catalyzed to produce hypochlorous acid $(\mathrm{HOCl})$ that is categorized as ROS, to respond for LPS challenge and/or kill other pathogens $[25,27,28]$. ROS primarily attack the polyunsaturated-fatty acids of cell and plasma membranes leading to the formations of MDA, a lipid peroxidation product $[27,29]$. Thus, the accumulation of MDA is commonly 


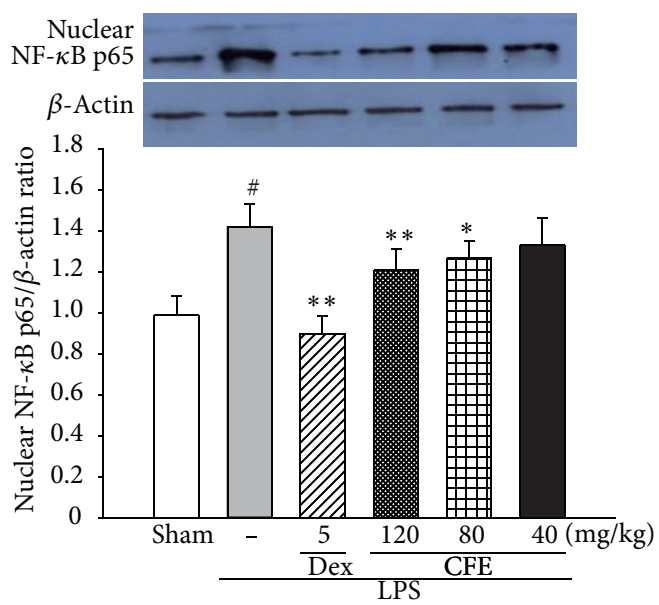

(a)

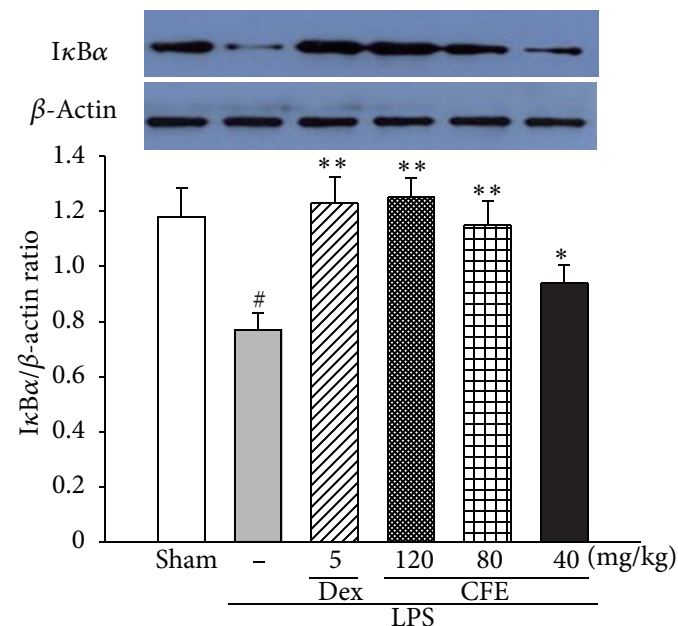

(c)

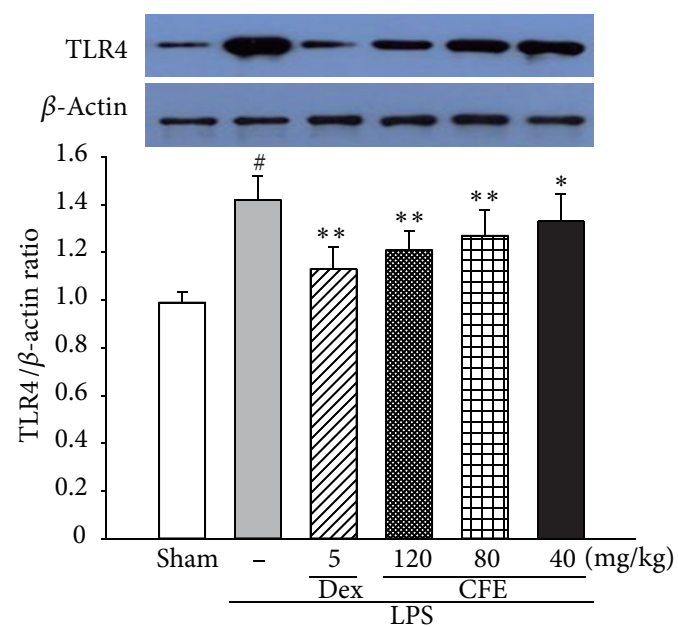

(e)

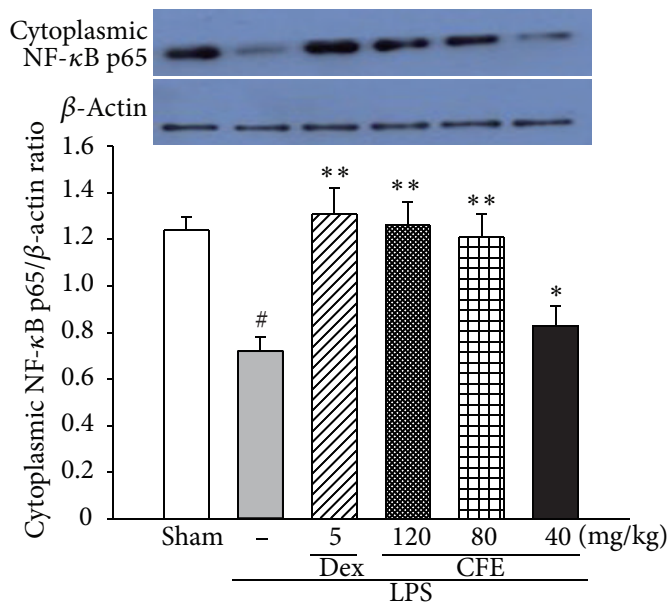

(b)

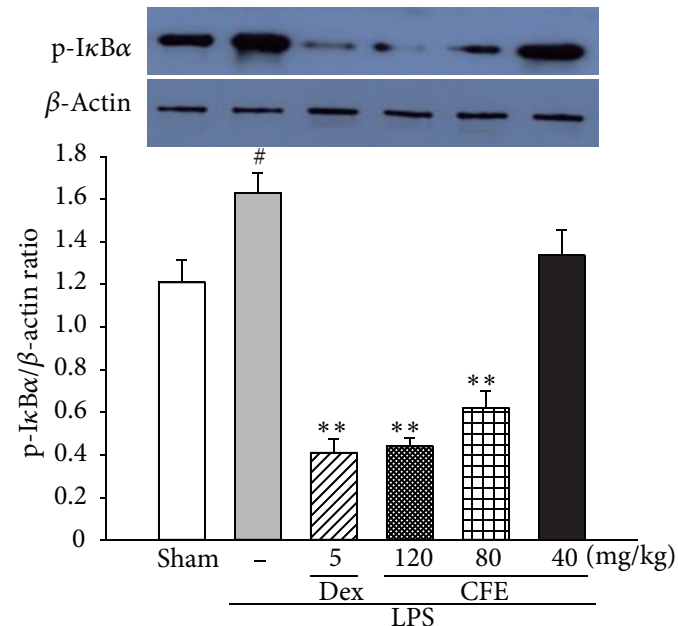

(d)

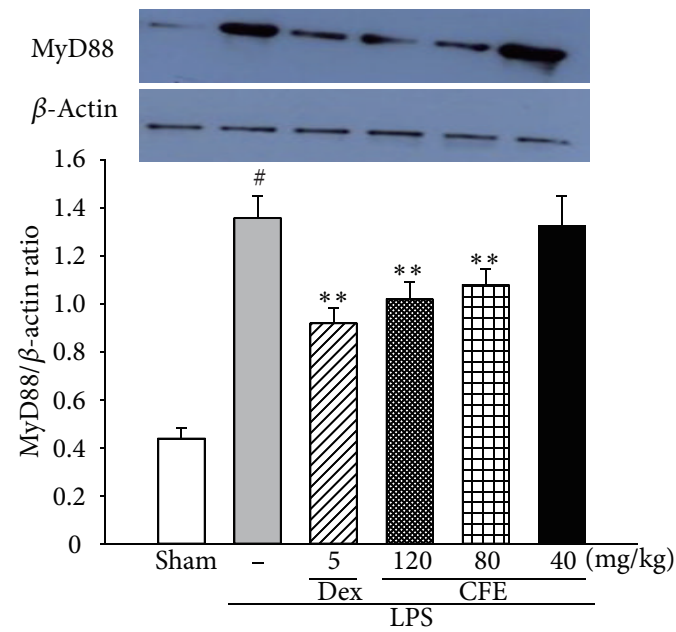

(f)

Figure 6: The effects of CFE on TLR4/MyD88/NF- $\kappa$ B expressions. The levels of NF- $\kappa$ B p65 in nucleus (a), NF- $\kappa$ B p65 in nucleus cytoplasm (b), $\mathrm{I} \kappa \mathrm{B} \alpha(\mathrm{c}), \mathrm{p}-\mathrm{I} \kappa \mathrm{B} \alpha(\mathrm{d})$, TLR4 (e), and MyD88 (f). Data was represented as the mean \pm SEM $(n=10) .{ }^{*} P<0.01$ compared to the sham group; ${ }^{*} P<0.05$ and ${ }^{* *} P<0.01$ compared to the LPS group. 
used as a marker to manifest the degree of lipid peroxidation, to some extent, the level of oxidative stress and antioxidant status $[26,29]$. With the results of MDA assay, pretreatment with CFE was found to have significant inhibitory effects on the formation of MDA, which clearly indicated that oxidative stress in lung tissues of ALI mice was alleviated. In addition, ROS have been proposed to mediate cell damage via a number of independent mechanisms including the inactivation of antioxidant defense systems consisting of a variety of antioxidant enzymes, such as SOD, CAT, and GPX $[25,29,30]$. These enzymes can minimize, scavenge, and eliminate the formation of ROS, protecting the host against oxidative stress-induced damage [30-32]. Hence, effective antioxidants can abate the oxidative stress of ALI by direct elimination of free radicals or by boosting defense systems of antioxidant enzymes $[26,30,32,33]$. In this study, CFE also markedly upregulated the activities of SOD, CAT, and GPx, which were observed to be markedly decreased in sepsisinduced ALI rodents $[34,35]$ and in the ALI patients clinically $[27,36]$. Therefore, combining with the results of MDA assay, we speculated that CFE could effectively reduce oxidative stress in ALI.

Clinical and experimental studies suggest that LPS induce the activation of alveolar macrophages and endothelial cells, which result in the productions of many proinflammatory and chemotactic cytokines $[15,37]$. TNF- $\alpha$, IL- $1 \beta$, and IL- 6 are well-characterized cytokines involved in the inflammatory responses of ALI [13, 38, 39]. These cytokines, combining with other proinflammatory factors, further stimulate neutrophils' infiltrations to migrate into lung tissues and initiate, amplify, and perpetuate the entire or focal inflammatory responses in ALI $[15,40]$. TNF- $\alpha$, mainly produced by monocytes/macrophages, is the earliest and primary endogenous mediator of the process of an inflammatory reaction and can elicit the inflammatory cascade, cause damage to the vascular endothelial cells, and induce alveolar epithelial cells to produce other cellular factors, such as IL-6 [40, 41]. Elevated TNF- $\alpha$ binds with a TNF- $\alpha$ acceptor in lung tissue, leading to the leakage of enzymes out of the organelle, which causes damage to the lung parenchyma [15]. IL-1 $\beta$ plays a key role in the progression of acute lung injury. It can inhibit fluid transportations across the distal lung epithelium to cause surfactant abnormalities and to increase protein permeability across the alveolar-capillary barrier [13]. IL-6 is one of the most common inflammatory cytokines, and its circulating levels have been shown to be excellent predictors of the severity of acute respiratory distress syndrome of different aetiologies, such as sepsis and acute pancreatitis $[15,40,42]$. In this present study, pretreatment with CFE significantly inhibited the production of TNF- $\alpha$, IL- $1 \beta$, and IL- 6 in lung. The inhibition of proinflammatory factors productions was in accordance with the protective effects of CFE against histopathologic damage. And the suppression of proinflammatory cytokines by CFE treatment was supposed to contribute to its protective effects against ALI.

$\mathrm{NF}-\kappa \mathrm{B}$ is an important nuclear transcription factor and plays a pivotal role in immune and inflammatory responses through the regulation of proinflammatory cytokines, chemokines, and adhesion molecules [12, 43, 44]. Uncontrolled activations of the NF- $\kappa \mathrm{B}$ pathways were involved in the pathogenesis of many acute and chronic inflammatory diseases, especially ALI $[43,45]$. In normal conditions, NF- $\kappa \mathrm{B}$ is sequestered in the cytoplasm by $\mathrm{I} \kappa \mathrm{Bs}$ $[46,47]$. Once activated, NF- $\kappa \mathrm{B}$ p 65 dissociates from its inhibitory proteins $\mathrm{I} \kappa \mathrm{B}$ and translocates from the cytoplasm to the nucleus where it triggers the transcription of specific target genes such as TNF- $\alpha$, IL- $1 \beta$, and IL-6 [37, 48]. To detect the inhibitory mechanism of TNF- $\alpha$, IL- $1 \beta$, and IL- 6 productions, we tested the effects of CFE on NF- $\kappa \mathrm{B}$ activation and $\mathrm{I} \kappa \mathrm{B}$ degradation [37]. With the stimulation of LPS, the levels of phosphorylated $\mathrm{I} \kappa \mathrm{B}$ protein and nucleus NF- $\kappa \mathrm{B}$ p 65 protein were remarkably increased. However, this tendency was reversed by CFE pretreatment, as western-blot analysis showed that $\mathrm{I} \kappa \mathrm{B}$ degradation and $\mathrm{NF}-\kappa \mathrm{B}$ p 65 activation were significantly blocked by pretreatment with CFE at the doses of $80 \mathrm{mg} / \mathrm{kg}$ and $120 \mathrm{mg} / \mathrm{kg}$. In addition, we found that $40 \mathrm{mg} / \mathrm{kg}$ of CFE did not affect $\mathrm{I} \kappa \mathrm{B}$ degradations and $\mathrm{NF}-\kappa \mathrm{B}$ p 65 activations statistically, in spite of the fact that it possessed inhibitory tendencies. Therefore, results suggested that the protective effects of CFE against LPS-induced ALI, to some extent, may be attributed to its roles in downregulation of NF- $\kappa$ B pathways.

LPS play key roles in the development and progression of ALI [5, 22, 49, 50]. TLR4, serving as an important pattern recognition receptor of host immune responses and essential upstream sensor for LPS from pathogens and microorganisms, would detect LPS and then trigger the activation of NF- $\kappa \mathrm{B}$ and its downstream responses through MyD88 dependent or independent pathways [5, 7, 49, 50]. Thus TLR4 is the fundamental upstream sensor for LPS $[7,11,49,51]$; it was necessary to probe whether the antiinflammation action of CFE exerted though TLR4-mediated pathways. Our data showed that the enhanced expressions of TLR 4 by LPS challenge were significantly downregulated with pretreatments of CFE at the doses of 80 and $120 \mathrm{mg} / \mathrm{kg}$, which corresponded with the level changes of $\mathrm{I} \kappa \mathrm{B} \alpha, \mathrm{NF}$ $\kappa \mathrm{B}$ p65, and other proinflammatory cytokines, in ALI mice lung tissues. Therefore, in conclusion, as shown in Figure 7 , we speculated that CFE could inhibit the binding of LPS to TLR4 in NF- $\kappa$ B signaling pathways, leading to reductions of proinflammatory cytokines productions and attenuations of pulmonary inflammatory responses. However, without any further experiments to eliminate the involvement of MyD88-independent pathway, we could not address and demonstrate the conclusion that TLR 4 activates NF- $\kappa \mathrm{B}$ via a MyD88-independent pathway. Therefore, explicit regulations of TLR4 signaling pathways by CFE require further studies.

\section{Conclusions}

The experimental evidence in this study demonstrated that CFE can effectively attenuate the LPS-induced ALI in mice. The protective effects of CFE were associated with the modulations of TLR4 signaling pathways. These experimental results suggested that CFE was a potential therapeutic drug for ALI. 


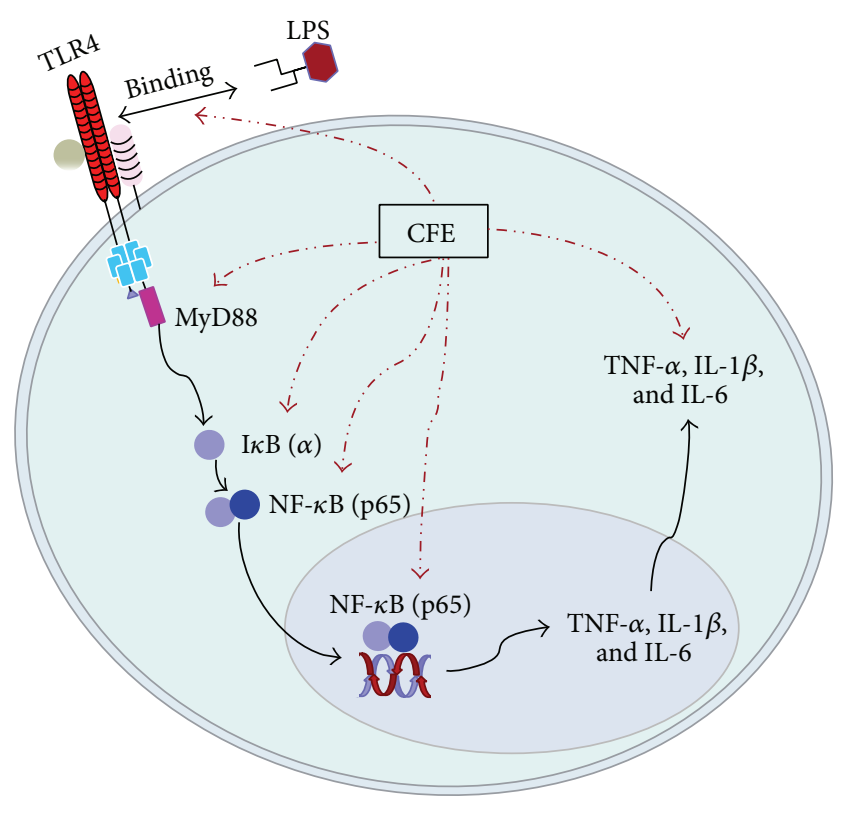

..> Inhibitory sites and effects

FIGURE 7: The underlying mechanism of CFE on the TLR4 signaling pathway. The red dotted arrows indicate the inhibitory sites and effects of CEF.

$\begin{array}{ll}\text { Abbreviations } \\ \text { CFE: } & \text { The supercritical-carbon dioxide fluid } \\ & \text { extract of Chrysanthemum indicum } \\ & \text { Linné } \\ \text { LPS: } & \text { Lipopolysaccharide } \\ \text { ALI: } & \text { Acute lung injury } \\ \text { ARDS: } & \text { Acute respiratory distress syndrome } \\ \text { MODS: } & \text { Multiple organ dysfunction syndrome } \\ \text { BALF: } & \text { Bronchoalveolar lavage fluid } \\ \text { ELISA: } & \text { Enzyme linked immunosorbent assay } \\ \text { Dex: } & \text { Dexamethasone } \\ \text { TNF- } \alpha: & \text { Tumor necrosis factor- } \alpha \\ \text { IL-1 } \beta: & \text { Interleukin-1 } \beta \\ \text { IL-6: } & \text { Interleukin-6 } \\ \text { MPO: } & \text { Myeloperoxidase } \\ \text { MDA: } & \text { Malondialdehyde } \\ \text { SOD: } & \text { Superoxide dismutase } \\ \text { CAT: } & \text { Catalase } \\ \text { GPx: } & \text { Glutathione peroxidase } \\ \text { TLR4: } & \text { Toll-like receptor } 4 \\ \text { MyD88: } & \text { Myeloid differentiation factor } 88 \\ \text { NF- } \kappa \text { B p65: } & \text { Nuclear factor kappa B p65 } \\ \text { I } \kappa \text { B } \alpha: & \text { Inhibitory kappa B alpha } \\ \text { ROS: } & \text { Reactive oxygen species } \\ \text { H\&E: } & \text { Hematoxylin and eosin. } \\ & \end{array}$

\section{Conflict of Interests}

The authors declare that there is no conflict of interests.

\section{Authors' Contribution}

Xiao-Li Wu and Xue-Xuan Feng contributed equally to this work.

\section{Acknowledgments}

This work was supported by grants from the Science and Technology Major Project of Guangdong Province (Project no. 2012A080202002), Guangdong Province Universities and Colleges Pearl River Scholar Funded Scheme (2011), and the National College Students' Innovative Entrepreneurial Training Plan Project (201310572024).

\section{References}

[1] L. B. Ware and M. A. Matthay, "The acute respiratory distress syndrome," The New England Journal of Medicine, vol. 342, no. 18, pp. 1334-1349, 2000.

[2] A. P. Wheeler and G. R. Bernard, "Acute lung injury and the acute respiratory distress syndrome: a clinical review," The Lancet, vol. 369, no. 9572, pp. 1553-1564, 2007.

[3] K. Atabai and M. A. Matthay, "The pulmonary physician in critical care -5 : acute lung injury and the acute respiratory distress syndrome: definitions and epidemiology," Thorax, vol. 57, no. 5, pp. 452-458, 2002.

[4] J. V. Diaz, R. Brower, C. S. Calfee, and M. A. Matthay, "Therapeutic strategies for severe acute lung injury," Critical Care Medicine, vol. 38, no. 8, pp. 1644-1650, 2010.

[5] Y. Imai, K. Kuba, G. G. Neely et al., "Identification of oxidative stress and Toll-like receptor 4 signaling as a key pathway of acute lung injury," Cell, vol. 133, no. 2, pp. 235-249, 2008.

[6] M. Zambon and J.-L. Vincent, "Mortality rates for patients with acute lung injury/ARDS have decreased over time," Chest, vol. 133, no. 5, pp. 1120-1127, 2008.

[7] T. Kaisho and S. Akira, "Toll-like receptor function and signaling," Journal of Allergy and Clinical Immunology, vol. 117, no. 5, pp. 979-987, 2006.

[8] M. Rojas, C. R. Woods, A. L. Mora, J. Xu, and K. L. Brigham, "Endotoxin-induced lung injury in mice: structural, functional, and biochemical responses," The American Journal of Physiology_Lung Cellular and Molecular Physiology, vol. 288, no. 2, pp. L333-L341, 2005.

[9] G. Matute-Bello, C. W. Frevert, and T. R. Martin, "Animal models of acute lung injury," American Journal of Physiology: Lung Cellular and Molecular Physiology, vol. 295, no. 3, pp. L379-L399, 2008.

[10] K. E. Driscoll, D. L. Costa, G. Hatch et al., "Intratracheal instillation as an exposure technique for the evaluation of respiratory tract toxicity: uses and limitations," Toxicological Sciences, vol. 55, no. 1, pp. 24-35, 2000.

[11] H. Z. Yang, J. P. Wang, S. Mi et al., "TLR4 activity is required in the resolution of pulmonary inflammation and fibrosis after acute and chronic lung injury," The American Journal of Pathology, vol. 180, no. 1, pp. 275-292, 2012.

[12] G. Bonizzi and M. Karin, "The two NF- $\kappa$ B activation pathways and their role in innate and adaptive immunity," Trends in Immunology, vol. 25, no. 6, pp. 280-288, 2004.

[13] M. T. Ganter, J. Roux, B. Miyazawa et al., "Interleukin-1beta causes acute lung injury via alphavbeta5 and alphavbeta6 
integrin-dependent mechanisms," Circulation Research, vol. 102, no. 7, pp. 804-812, 2008.

[14] M. R. Looney, X. Su, J. A. van Ziffle, C. A. Lowell, and M. A. Matthay, "Neutrophils and their Fc $\gamma$ receptors are essential in a mouse model of transfusion-related acute lung injury," Journal of Clinical Investigation, vol. 116, no. 6, pp. 1615-1623, 2006.

[15] M. Bhatia and S. Moochhala, "Role of inflammatory mediators in the pathophysiology of acute respiratory distress syndrome," Journal of Pathology, vol. 202, no. 2, pp. 145-156, 2004.

[16] W. Cheng, J. Li, T. You, and C. Hu, "Anti-inflammatory and immunomodulatory activities of the extracts from the inflorescence of Chrysanthemum indicum Linné," Journal of Ethnopharmacology, vol. 101, no. 1-3, pp. 334-337, 2005.

[17] X. L. Wu, C. W. Li, and H. M. Chen, "Anti-inflammatory effect of supercritical-carbon dioxide fluid extract from flowers and buds of chrysanthemum indicum linnen," Evidence-Based Complementary and Alternative Medicine, vol. 2013, Article ID 413237, 13 pages, 2013.

[18] J. Su, L. Tan, P. Lai et al., "Experimental study on antiinflammatory activity of a TCM recipe consisting of the supercritical fluid $\mathrm{CO}_{2}$ extract of Chrysanthemum indicum, Patchouli Oil and Zedoary Turmeric Oil in vivo," Journal of Ethnopharmacology, vol. 141, no. 2, pp. 608-614, 2012.

[19] G. U. Meduri, A. S. Headley, E. Golden et al., "Effect of prolonged methylprednisolone therapy in unresolving acute respiratory distress syndrome: a randomized controlled trial," The Journal of the American Medical Association, vol. 280, no. 2, pp. 159-165, 1998.

[20] D. Cornélio Favarin, M. Martins Teixeira, E. Lemos De Andrade et al., "Anti-inflammatory effects of ellagic acid on acute lung injury induced by acid in mice," Mediators of Inflammation, vol. 2013, Article ID 164202, 13 pages, 2013.

[21] J. Gao, Y. Zhan, J. Chen, L. Wang, and J. Yang, "Triptolide ameliorates lipopolysaccharide-induced acute lung injury in rats," European Journal of Medical Research, vol. 18, article 58, 2013.

[22] D. S. Faffe, V. R. Seidl, P. S. C. Chagas et al., "Respiratory effects of lipopolysaccharide-induced inflammatory lung injury in mice," European Respiratory Journal, vol. 15, no. 1, pp. 85-91, 2000.

[23] N. Borregaard, O. E. Sørensen, and K. Theilgaard-Mönch, "Neutrophil granules: a library of innate immunity proteins," Trends in Immunology, vol. 28, no. 8, pp. 340-345, 2007.

[24] K. Kawabata, T. Hagio, and S. Matsuoka, "The role of neutrophil elastase in acute lung injury," European Journal of Pharmacology, vol. 451, no. 1, pp. 1-10, 2002.

[25] H. Zhang, A. S. Slutsky, and J. L. Vincent, "Oxygen free radicals in ARDS, septic shock and organ dysfunction," Intensive Care Medicine, vol. 26, no. 4, pp. 474-476, 2000.

[26] C. W. Chow, M. T. H. Abreu, T. Suzuki, and G. P. Downey, "Oxidative stress and acute lung injury," The American Journal of Respiratory Cell and Molecular Biology, vol. 29, no. 4, pp. 427431, 2003.

[27] J. Macdonald, H. F. Galley, and N. R. Webster, "Oxidative stress and gene expression in sepsis," British Journal of Anaesthesia, vol. 90, no. 2, pp. 221-232, 2003.

[28] M. Faurschou and N. Borregaard, "Neutrophil granules and secretory vesicles in inflammation," Microbes and Infection, vol. 5, no. 14, pp. 1317-1327, 2003.

[29] D. Del Rio, A. J. Stewart, and N. Pellegrini, "A review of recent studies on malondialdehyde as toxic molecule and biological marker of oxidative stress," Nutrition, Metabolism and Cardiovascular Diseases, vol. 15, no. 4, pp. 316-328, 2005.

[30] V. M. Victor, M. Rocha, and M. de la Fuente, "Immune cells: free radicals and antioxidants in sepsis," International Immunopharmacology, vol. 4, no. 3, pp. 327-347, 2004.

[31] J. Ueda, M. E. Starr, H. Takahashi et al., "Decreased pulmonary extracellular superoxide dismutase during systemic inflammation," Free Radical Biology and Medicine, vol. 45, no. 6, pp. 897904, 2008.

[32] J. D. Lang, P. J. McArdle, P. J. O’Reilly, and S. Matalon, “Oxidantantioxidant balance in acute lung injury," Chest, vol. 122, no. 6, pp. 314S-320S, 2002.

[33] H.-S. Kang, H.-M. Park, H.-K. Go, S. Kim, J. Kim, and G. Kim, "Effect of antioxidant in an acute lung injury animal model," Korean Journal of Chemical Engineering, vol. 29, no. 11, pp. 15911596, 2012.

[34] X. Xiao, M. Yang, D. Sun, and S. Sun, "Curcumin protects against sepsis-induced acute lung injury in rats," Journal of Surgical Research, vol. 176, no. 1, pp. e31-e39, 2012.

[35] J. Xie, H. Di, H. Li, X. Cheng, Y. Zhang, and D. Chen, "Bupleurum chinense DC polysaccharides attenuates lipopolysaccharide-induced acute lung injury in mice," Phytomedicine, vol. 19, no. 2, pp. 130-137, 2012.

[36] V. L. Kinnula and J. D. Crapo, "Superoxide dismutases in the lung and human lung diseases," American Journal of Respiratory and Critical Care Medicine, vol. 167, no. 12, pp. 1600-1619, 2003.

[37] T. Bouwmeester, A. Bauch, H. Ruffner et al., "A physical and functional map of the human TNF-alpha/NF-kappa B signal transduction pathway," Nature Cell Biology, vol. 6, no. 2, pp. 97105, 2004.

[38] M. Kolb, P. J. Margetts, D. C. Anthony, F. Pitossi, and J. Gauldie, "Transient expression of IL-1 $\beta$ induces acute lung injury and chronic repair leading to pulmonary fibrosis," Journal of Clinical Investigation, vol. 107, no. 12, pp. 1529-1536, 2001.

[39] X. Tang, D. Metzger, S. Leeman, and S. Amar, "LPS-induced TNF- $\alpha$ factor (LITAF)-deficient mice express reduced LPSinduced cytokine: evidence for LITAF-dependent LPS signaling pathways," Proceedings of the National Academy of Sciences of the United States of America, vol. 103, no. 37, pp. 13777-13782, 2006.

[40] J. Scheller, A. Chalaris, D. Schmidt-Arras, and S. Rose-John, "The pro- and anti-inflammatory properties of the cytokine interleukin-6," Biochimica et Biophysica Acta: Molecular Cell Research, vol. 1813, no. 5, pp. 878-888, 2011.

[41] S. Mukhopadhyay, J. R. Hoidal, and T. K. Mukherjee, "Role of TNF $\alpha$ in pulmonary pathophysiology," Respiratory Research, vol. 7, article 125, 2006.

[42] A. A. Birukova, Y. Tian, A. Meliton, A. Leff, T. Wu, and K. G. Birukov, "Stimulation of Rho signaling by pathologic mechanical stretch is a "second hit" to Rho-independent lung injury induced by IL-6," American Journal of Physiology-Lung Cellular and Molecular Physiology, vol. 302, no. 9, pp. L965L975, 2012.

[43] P. Moine, R. McIntyre, M. D. Schwartz et al., "NF- $\kappa$ B regulatory mechanisms in alveolar macrophages from patients with acute respiratory distress syndrome," Shock, vol. 13, no. 2, pp. 85-91, 2000.

[44] R. B. Goodman, J. Pugin, J. S. Lee, and M. A. Matthay, "Cytokine-mediated inflammation in acute lung injury," Cytokine and Growth Factor Reviews, vol. 14, no. 6, pp. 523-535, 2003. 
[45] S. Yuan, S. Huang, W. Zhang et al., "An amphioxus TLR with dynamic embryonic expression pattern responses to pathogens and activates NF- $\kappa$ B pathway via MyD88," Molecular Immunology, vol. 46, no. 11-12, pp. 2348-2356, 2009.

[46] G. P. Nolan, S. Ghosh, H. Liou, P. Tempst, and D. Baltimore, "DNA binding and $\mathrm{I} \kappa \mathrm{B}$ inhibition of the cloned p 65 subunit of NF- $\kappa$ B, a rel-related polypeptide," Cell, vol. 64 , no. 5, pp. 961969, 1991.

[47] A. A. Beg and A. S. Baldwin Jr., "The I $\kappa$ B proteins: multifunctional regulators of Rel/NF- $\kappa \mathrm{B}$ transcription factors," Genes and Development, vol. 7, no. 11, pp. 2064-2070, 1993.

[48] D. Jarrar, J. F. Kuebler, L. W. Rue III et al., "Alveolar macrophage activation after trauma-hemorrhage and sepsis is dependent on NF- $\kappa \mathrm{B}$ and MAPK/ERK mechanisms," The American Journal of Physiology-Lung Cellular and Molecular Physiology, vol. 283, no. 4, pp. L799-L805, 2002.

[49] A. E. Medvedev, K. M. Kopydlowski, and S. N. Vogel, "Inhibition of lipopolysaccharide-induced signal transduction in endotoxin-tolerized mouse macrophages: dysregulation of cytokine, chemokine, and Toll-like receptor 2 and 4 gene expression," Journal of Immunology, vol. 164, no. 11, pp. 55645574, 2000.

[50] S. Jeyaseelan, H. W. Chu, S. K. Young, M. W. Freeman, and G. S. Worthen, "Distinct roles of pattern recognition receptors CD14 and Toll-like receptor 4 in acute lung injury," Infection and Immunity, vol. 73, no. 3, pp. 1754-1763, 2005.

[51] M. Tohno, T. Shimazu, H. Aso, Y. Kawai, T. Saito, and H. Kitazawa, "Molecular cloning and functional characterization of porcine MyD88 essential for TLR signaling," Cellular \& Molecular Immunology, vol. 4, no. 5, pp. 369-376, 2007. 


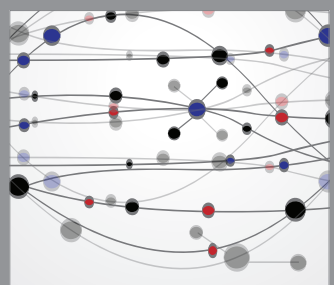

The Scientific World Journal
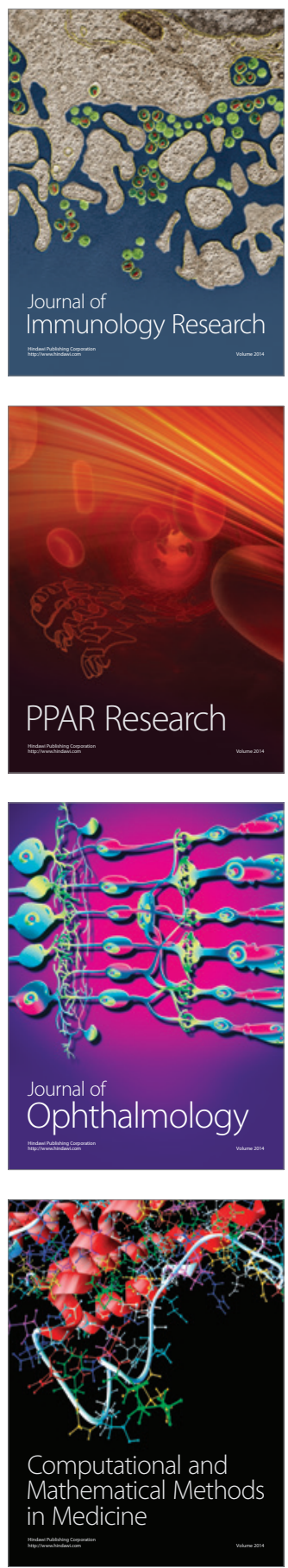

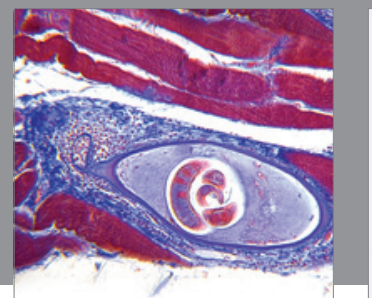

Gastroenterology

Research and Practice
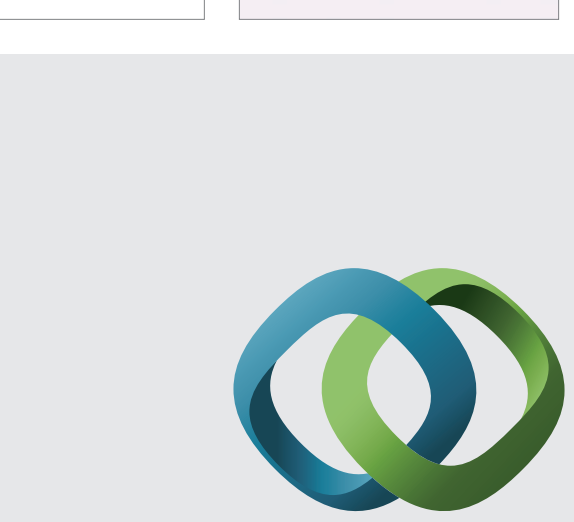

\section{Hindawi}

Submit your manuscripts at

http://www.hindawi.com
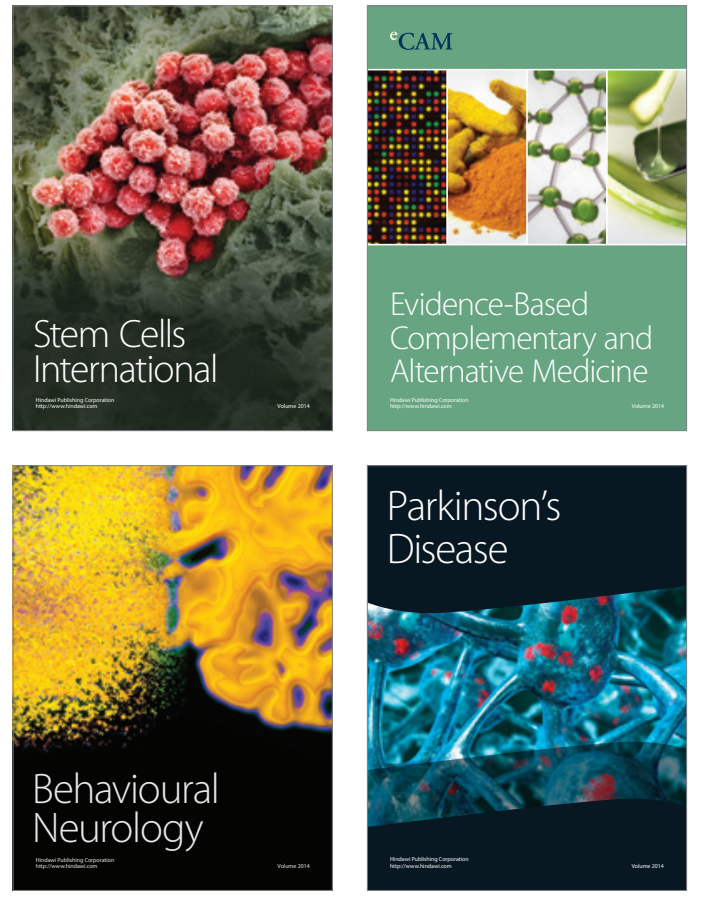
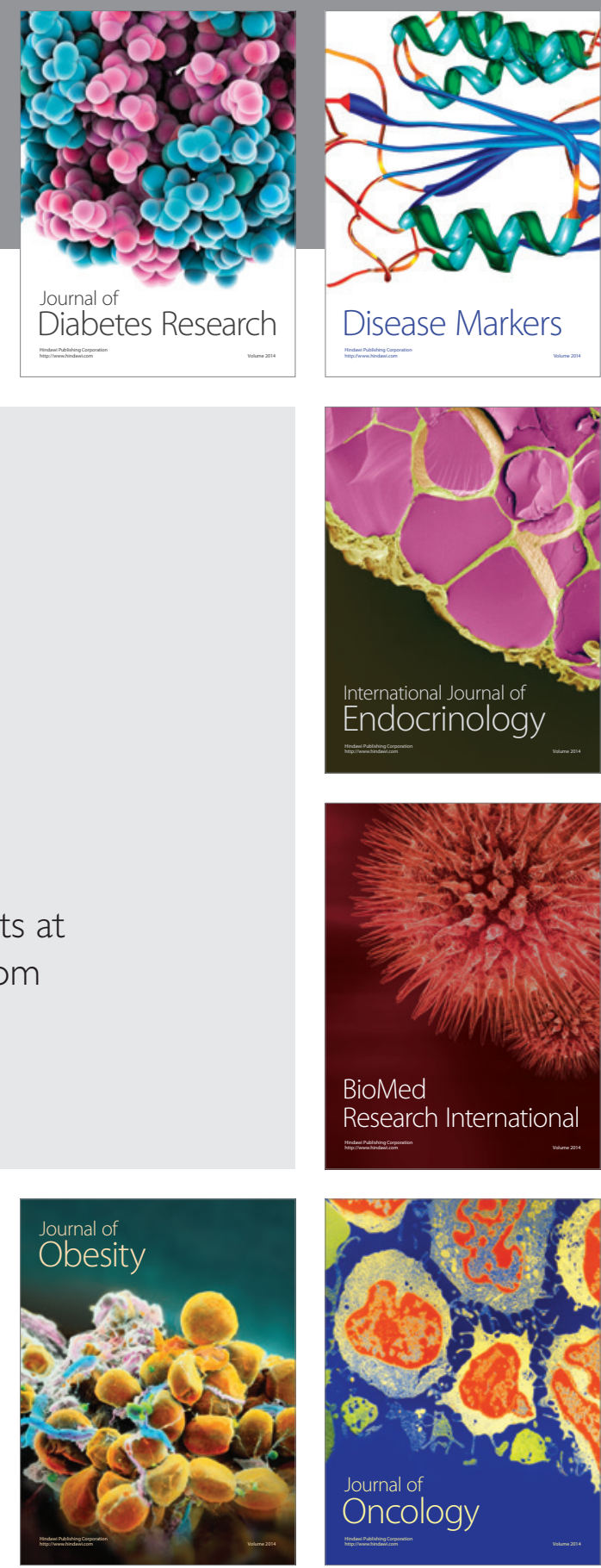

Disease Markers
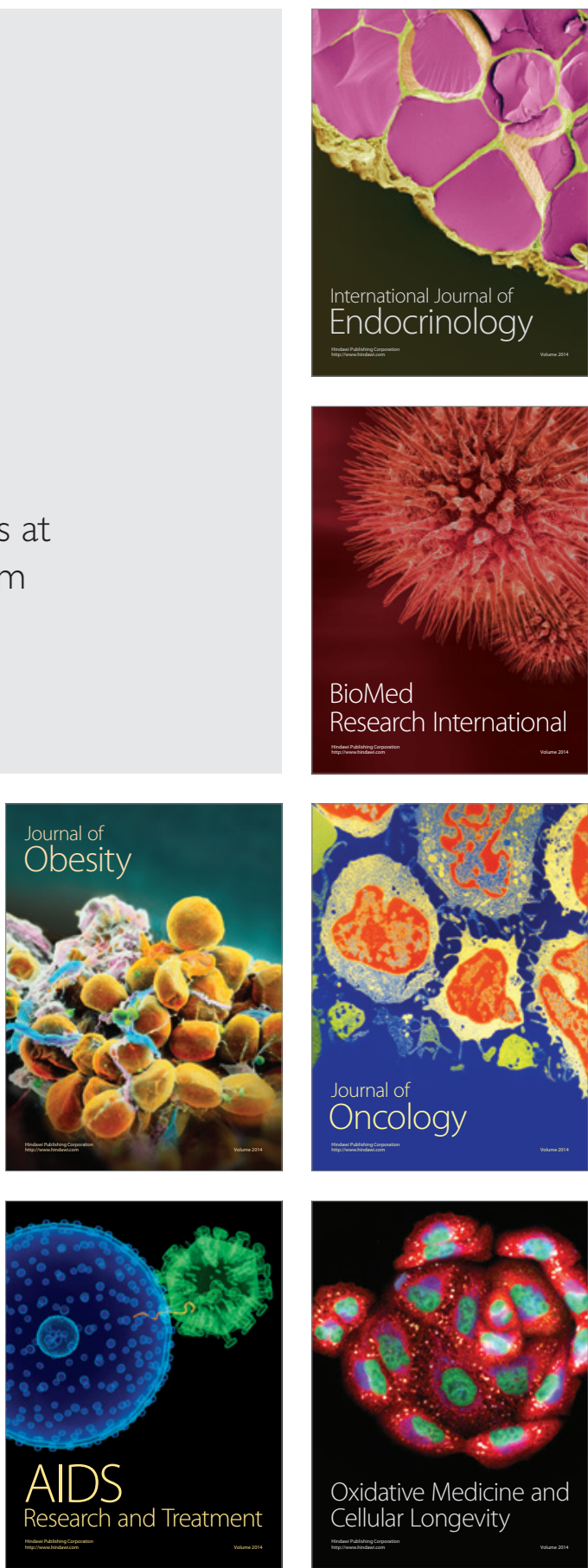